\title{
THE REPRESENTATION OF DICTION AND SOUND IN MUSIC AS THERAPY IN SELECTED GHALLYWOOD AND NOLLYWOOD MOVIES: A CASE STUDY OF PASSION OF THE SOUL (2008) BY FRANK RAJAH ARASE AND A CRY FOR HELP (2002) BY ANDY AMENECHI
}

\author{
Shaka Ha_an Odilia and Afutendem Lucas Nkwetta \\ University of Dschang, Research Centre in Space, Arts and Humanities (CEREAH), \\ Research Group in English and Commonwealth Studies
}

\begin{abstract}
This work investigates and examines how music is represented therapeutically in movies from Africa. Music is the combination of sounds, instruments and words with a view of beauty of form and the expression of thought or feeling. Traditional African music is woven around every event; from birth through to death. Music therapy is the art of using musical sounds in bringing about changes from undesirable unhealthy conditions. The research gap we cover is how diction and sound are represented in movies and incorporated in the wellness process. Apart from medicines produced in laboratories, are there any other sources of therapy? How can music be represented in media to treat patients? The hypotheses are diction and sound in music are therapeutic and apart from getting well through the intake of hospital drugs, we can also go in for soft treatment in the form of music. This is represented through construction, using filmic language, codes and conventions. Structuralist Film Theory and Cultural Film Theory are used as theoretical framework and in analyzing the movies. Data was collected using the simple survey design wherein a qualitative analysis of data was done by reading two movies which were purposely selected to represent music as therapy: Passion of the Soul by Franck Rajah and A Cry for Help by Amenechi. The analysis and results reveal that music is indeed therapeutic as many sick cases both spiritual and psychological are healed through music in the two movies.
\end{abstract}

Keywords: language, representation, music, movies, therapy, theories

\section{BACKGROUND TO THE STUDY}

The rise of the African film industry can be traced back to the decolonisation period of the continent around the early $20^{\text {th }}$ century. Like other forms of creative expression by Africans, filmmaking constitutes a form of discourse and practice that is not just artistic and cultural, but also intellectual, religious, political and medicinal. A significant portion of African cinema has 
International Journal of Arts and Humanities

ISSN: 2581-3102

Volume: 04, Issue: 02 "February 2020"

focused and continues to focus on thematic issues of racism, love and marriage, colonial exploitation and injustice, tradition and modernity, hopes, betrayals and disaffections of independence, immigration and many other social justice issues. African cinema is a way of defining, describing and interpreting African experiences with those forces that have shaped their past and that continue to shape and influence the present.

Contemporary Nigeria dates from 1914, when the British Protectorates of Northern and Southern Nigeria were joined. The country became independent on October 1, 1960, and in 1963 adopted a republican constitution but elected to stay a member of the Commonwealth of Nations. It is bordered to the north by Niger, to the east by Chad and Cameroon, to the south by the Gulf of Guinea of the Atlantic Ocean and to the west by Benin. There are an estimated 250 ethnic groups in Nigeria, amongst which the largest are: the Hausa-Fulani, the Yoruba and Igbo. At the beginning of the 20th century, most Nigerians were followers of traditional religions, but British colonial policies discouraged this to such an extent that by independence in 1960, the majority of the people were classified as Muslims or Christians.

Today cinema is vibrant in Nigeria and she has witnessed a high production estimated of 1000 to 1500 movies per year. Her movies industry is termed Nollywood which is the second largest after the Bollywood. Movies as a medium first arrived Nigeria in the late $19^{\text {th }}$ century in the form of peephole viewing of motion pictures. This were replaced in the $20^{\text {th }}$ century with improved motion pictures exhibition devices with the first set of movies screened at the Glover Memorial Hall in Lagos in 1903. However, television broadcasting in Nigeria began in the 1960s and by the mid-1960s, every state had its own broadcasting station. Laws limited foreign television content so, producers in Lagos began televising popular theatre productions. Many of these were circulated in videos and a small scale informal video movie trade developed.

Nigeria's rich and varied cultural heritage derives from the mixture of its ethnic groups with Arabic and western European influences. The country combines traditional culture with other African and international urban sophistication. The vibrant popular culture reflects great changes in inherited traditions and adaptations of imported ones. Music and dance are integral to both African and Nigerian culture, and each ethnic group has its own specialties. Traditional instruments include various types of flutes, trumpets, musical bows, xylophones, and wooden clappers, as well as many varieties of drums. Music is used to celebrate rulers and to accompany public assemblies, weddings and funerals, festivals, and storytelling.

Ghana is also a West African, situated on the coast of the Gulf of Guinea. It was the first black African country south of the Sahara to achieve independence from colonial rule on 6 March 1957 and remains a member of the Commonwealth. Ethnically, the people of Ghana may be said to belong to one broad group within the African family, but there is a large variety of subgroups. 
International Journal of Arts and Humanities

ISSN: 2581-3102

Volume: 04, Issue: 02 "February 2020"

On the basis of language, it is possible to distinguish at least 75 of these. Many of these are very small, and only 10 of them are numerically significant. The largest of these groups are the Akan, Baule, Fante, Guang, Molo-Dagbani, Ewe, Ga-Adangme and Gurma. More than one-half of the population is Christian, about one-fifth is Muslim, and a small segment adheres to the traditional indigenous religions. Though they are based, in general, on belief in the existence of a supreme being, a number of lesser deities associated with various natural phenomena are recognized. Considerable prominence is given to dead ancestors, who are considered to be ever-present, capable of influencing the course of events for the living and capable of serving as intermediaries between the living and the gods.

In all parts of the country the cultural heritage is closely linked with religion and the institution of chieftaincy. Various festivals and rites are centred on chieftaincy and the family and are occasioned by such events as harvest, marriage, birth, puberty, and death. Major health problems in Ghana include communicable diseases, poor sanitation, and poor nutrition. The main emphasis of government health policy is on improved public health, and, since independence, many improvements have been made in nutrition and in maternal and child care. Many of the endemic diseases, such as malaria, pneumonia, and diseases of the gastroenteritis group, which formerly took a heavy toll of life, have been brought under a measure of control as a result of improved hygiene, better drugs, and education. However, most communities still have inadequate sanitation and water-supply facilities, which hinders efforts to improve public health. Although AIDS is present in the country, Ghana has made strides in combatting the disease. The reported HIV infection rate is similar to or lower than many other countries in Africa.

African cinema is a product of the historical experiences of Africans which is vital to the challenges that African societies face in our contemporary world and why not in the future. Thus, filmmaking provides one of the most productive sites for experiencing, understanding and appreciating such diversity and complexity. Filmmaking has been flourishing in Ghana till date after its introduction to the British colony of Gold Coast, now Ghana in 1923. Ghana's film industry might not be as popular as Nigeria's Nollywood, but it is growing fast. Talented filmmakers and actors from the country have been travelling the world to further their careers and are now making movies back home. The origins of film production in Nigeria and Ghana can be traced back to the Ghanaian capital, Accra. A group of young directors were tasked with creating films at a film institute in Accra, with some then going off to Nigeria and the rest staying in Ghana. The National Film and Television Institute (NAFTI), established in 1978, is where a new generation of filmmakers are new creating.

Music being ubiquitous in all cultures has been explored greatly by African cinema and it is used for different purposes ranging from entertainment, healing, praise and worship, communication to recreation. As such the Nigerian and Ghanaian film industries are not left out in emphasizing 
International Journal of Arts and Humanities

ISSN: 2581-3102

Volume: 04, Issue: 02 "February 2020"

the therapeutic effects of music in our daily lives through their movies. This research work is focused on the representation of music as therapy a case study of Frank Rajah's Passion of the Soul and Andy Amenechi's A Cry for Help. Music plays an invaluable role in our lives and is used differently across cultures for various purposes and listened to by persons of all ages, races and ethnic backgrounds. Not surprisingly, different kinds of music appeal to persons of different ages and ethnic backgrounds and the same persons may desire different kinds of music under different circumstances. Since ancient times, music has been used to enhance well-being and reduce pain and suffering wherein tablets failed. This paper analyses the medically relevant effects of music; focusing on pain, anxiety and mood. Providing music in a hospital ward or in waiting areas can create a positive milieu for patients, families and staff to communicate. Creating such an environment can have significant effects on patient's moods in terms of anxiety, depression and perceived stress. By singing or listening to music, people suffering from pain or depression feel relieved. In this case music acts as their own therapy. Equally, music therapy helps improve the quality of life for dying patients. In working with persons who are dying, it fosters supportive interactions between patients and loved ones and helps patients connect with and express emotions in a less threatening manner and why not bring patients back to life as in the case of a coma. Music also works like magic for people suffering from dementia and memory loss as it helps in restoring their senses. Generally, music has different effects based on listener characteristics such as age, culture, medical conditions that affect hearing, musical aptitude and experience. Other factors enhancing musiceffectiveness in therapy include elements of music (tempo, pitch, harmony, melody, rhythm), means of delivery (headphones, speaker, open air, live versus recorded), setting (group or alone) and active versus passive participation. This paper analyses how Rajah and Amenechi represent and incorporate music as therapy in movies; by bringing out the health benefits that come with listening or singing music ranging from physical, psychological and spiritual benefits. Hence, Ghallywood and Nollywood film industries have succeeded to showcase the healing power of music in their movies

\section{THE RESEARCH PROBLEM, QUESTIONS AND HYPOTHESES}

People listen to music for entertainment purposes but fail to understand that music can work where all other forms of medication such as tablets, capsules, injections have failed. The lyrics and the sound of music listened to at the right time by people of all groups, race and cultures can enact tremendous health ameliorations. Hence the therapeutic ability of music to heal cannot be underestimated as it helps people to reconnect with the world by stimulating the brain, lessening stress and anxiety, reducing depression, improving mood, lessening feelings of isolation and loneliness and fostering happiness and pleasure. We then pose these questions: apart from music proposed in laboratories, are there any other sources of therapy? How is diction and sound in music represented as therapy in movies? How are patients or people treated with music? 
International Journal of Arts and Humanities

ISSN: 2581-3102

Volume: 04, Issue: 02 "February 2020"

The hypotheses are apart from physical drugs there is music that can act as medicines. The diction and sound in music contain soft therapeutic elements that should be considered in treating certain illnesses.

\section{THEORETICAL FRAMEWORK AND LITERATURE REVIEW}

Two theories were used to analyse this work, the Structuralist Film Theory and Film Theory and Approach to Criticism. The Structuralist Film Theory is a branch of film theory that is rooted in structuralism, itself based on structural linguistics of Ferdinand de Saussure which developed in Europe in the early 1900s. Structuralist Film Theory emphasises how films convey meaning through the use of codes and conventions not dissimilar to the way languages are used to construct meaning in communication. This theory aims at giving the movie-goers a taste of what a film of any genre is all about. To present the very essence of a film, making the viewing public realize and understand the potential and the very core significance of a film, presenting a film in structures that can make the audience easily adapt into by means of the usage of structural techniques such as movie elements that effortlessly grab the curiosity and attention of an individual or a group of people mostly as a whole, to make a movie goer see how a movie is all about not just through his or her eyes but also through his or her perusing mind and human understanding. Structuralist Film Theory desires to make it known that a movie is not just a mere film flickering in the silver screen of a cinema house but also a much broader reflection of the daily life of every individual of all ages, ranks and race, in short, every single person in all aspects of life. It aims to teach people how to appreciate, how to understand and how to relate to a movie down to its tiniest details. Capturing people's fancies and interest, making them relate themselves and their lives and day-to-day lifestyles to a movie's sound score, a movie's sound effects, the movies themes and most of the time gripping scenes, and even the actor's portrayal of a character, and most of all it aims to probe deep in the heart of every movie going, capturing their very emotions and making them fall in love down to the smallest aspect and details of a particular film. The Cultural Film Theory focuses on how films reflect the culture in which they are made with the goal of understanding how meaning is constructed in a society's social, historical, political, economic and religious context. Lots of works have been reviewed as far as music therapy is concerned. In a study carried out by Kenneth Aigen (1991), an adequate conception of music therapy demands a view of music specific to the clinical milieu. The view of music promoted here has implications for training, research and clinical practice in music therapy as it contributes to a conceptual worldview for music therapists. Discussing issues of definition and function, this author argues that exploring the original functions of music can shed light on the mechanisms of clinical music therapy process. This original function is seen in shamanic and other ritual uses of music that contain analogues to the clinical milieu. A personal vision of music is offered that connects these thoughts on shamanism and its relevance for 
International Journal of Arts and Humanities

ISSN: 2581-3102

Volume: 04, Issue: 02 "February 2020"

therapy to current psychological and ecological crises. A unique role for music therapy is then proposed in regards to these contemporary ills. Charles O. A (2010), in another paper examines the present state of music therapy in Nigeria. In doing this, he discusses music therapy, the scope of operation and competence of the therapists, their trainings and dispositions. In the same vein, he examines the critical needs of the Nigerian music therapist in consonance with the people's beliefs. As a result of this, he advocates that the training of Nigerian music therapists should incorporate cultural realities of the people; that researches should be intensified, taken to higher heights and that for their activities to be known in Nigeria, they must function under a known and registered body.

Little wonder the ancient Greeks assigned the god Apollo to reign over both music and healing, Trehan, (2004). Plato prescribed both music and dancing for the fearful and anxious while Aristotle spoke of the power of music to restore health and normalcy to those who suffer from uncontrollable emotions and compared it to medical treatment, Gallant and Holosko (1977). Whether music can really heal is not in doubt but convincing strides should be taken to demonstrate it. According to Dawn Kent (2006), music has a vast influence over the nations and people on this planet. It has been used in every culture and is often connected with anxiolytic and analgesic properties. Today, it is used in many hospitals to help patients relax and help relieve or ease pain, confusion and anxiety. Music is also commonly used in counseling. Music therapy techniques may include guided listening or improvisational playing and are used within the context of many theories and for many types of mental disorders from depression to schizophrenia. Many of the healing qualities of music in counseling are connected to its use as a nonverbal medium for communication. Music is read differently in the brain than nonmusical tones and is connected to many different areas of the brain. Learning music relegates a larger part of the brain to recognizing and interpreting music. Listening to music has also been found to have an effect on learning. A survey studying the difference in GPA between students who listen to music while studying and those who do not find no overall significant difference but does find that students who listen to hiphop and rap while studying score significantly lower while students who listen to easy listening and classical are likely to have higher GPAs. In addition, music has been found to produce a relaxed mood and stress reduction making it a plausible way to accommodate coping with pain and anxiety, Hendricks, Robinson, Bradley \& Davis, (1999). The importance of music in life cannot be overemphasized. A lot of extensive research has been carried out on music and music therapy as a whole and the healing tendencies it has but none has dwelt on the representation of diction and sound in music as therapy in African films. So, the specificity of this work lies in the fact that it analyses the therapeutic benefits of music in two selected movies. That is Passion of the Soul and A Cry for Help.

\section{METHODOLOGY AND ANALYSES}




\section{International Journal of Arts and Humanities}

ISSN: 2581-3102

Volume: 04, Issue: 02 "February 2020"

This study is out to investigate how music is represented as therapy in Nollywood and Ghallywood movies and to carry out this study, an analysis of the two selected movies Passion of the Soul and A Cry for Help directed by Franck Rajah and Andy Amenechi isdone. The two directors have a point of convergence when they both use music to show its therapeutic purposes. We came out with many instances the directors portray music as therapy in the two movies. In this case any instances where music was used to heal a person either psychologically, spiritually or physically. We realized equally that the directors portray music as food for the soul as there are several instances where music is used to reduce stress and depression and why not improve the mood of characters in certain obnoxious situations. We chose the descriptive and interpretive method to show fully and effectively how music is represented as therapy in both movies and how patients are healed using music.

\subsection{Summary of Corpus}

Here, we are going to give a recapitulation of the two selected films to be used for this study. That is A Cry for Help (Nollywood) and Passion of the Soul (Ghallywood). Passion of the Soul is a passionate, romantic love story that revolves around Najah role played by Jackie Appiah and Joe role played by Majid Michel. These two are so much in love that one may be tempted to say they were destined to be but Najah's father; justice Sarbah vows that this love encounter must end as his beautiful and adorable daughter must marry his friend's son; Jerry. His reasons are simple, this friend of his helped him to be the justice he is and besides his daughter's wellbeing will be guaranteed since the said friend is wealthy and so is his son; unlike Joe who is comparatively a nobody. Najah and Joe go through lots of rough times and music is the only thing that comforts them during such dark moments. The movie commences with Najah's traditional wedding accompanied with some soft music sang by her maid as Najah is completely depressed and teary. As fate may have it, Najah discovers she is pregnant for Joe but she must marry Jerry to make her father happy. Meanwhile Joe in his frustration plays the guitar which help reduces his stress but unfortunately for him, his friends involve him in a criminal act wherein he is caught and jailed. Thanks to Najah's intervention, he is freed with the help of her father. Since Najah's pregnancy is still a secret, she is taken to an orphanage to be taken care of until she gives birth while her husband is out of the country on a business trip. Coincidentally, it is Joe's mother who is in charge of her; unaware that she is her son's love until it is delivery time where Joe on passing sees her being rushed to the maternity. Justice Sarbah strikes a deal with Joe, gives the baby to him immediately after delivery. She later tells him Najah died thereafter, while Najah is made to understand that the baby died at birth. Joe in his distress loses his mother and music is the only therapy he has left. He finally falls in love with another lady; Eve who fools him and makes away with his money. As destiny may have, Joe and Nash now policemen are asked to investigate a murder case. It is thanks to this that they meet again and after lots of 
International Journal of Arts and Humanities

ISSN: 2581-3102

Volume: 04, Issue: 02 "February 2020"

turmoil and suspicion their love rejuvenates again. A lot of truths come to the limelight and Najah confronts her father for being such a devil in disguise. She equally discovers that her husband is behind lots of crimes. At this time her baby with Joe is in a critical situation as she suffers from heart attack and is in need of a transplant. Najah's father offers his, Jerry is sentenced to fifteen years imprisonment while Najah, Joe and their baby live happily ever after.

A Cry for Help is a very pathetic and sorrowful movie that centers around the agonies of an orphan, Blessing, a role played by Nkiru Syvanus. All through her life she suffers from one tribulation to another and music happens to be her therapy in such critical moments. When the movie commences, she is crying and singing on her parent's graves then later she moves to the city to live with her uncle; Uwoechi role played by Clem Ohameze just to make ends meet as staying in the village only makes her sober. While in the city she suffers from many trials and agonies. Firstly, she works as a maid and salesgirl but is accused of theft in both situations. Her uncle who is always there for her looks for another job for her in a restaurant but her employer uses her girls for prostitution which she refuses to abide and consequently loses the job. At this juncture she becomes a vagabond as she cannot go back to her uncle again as she has over tormented him. Thanks to a good Samaritan who picks her up and she finds herself in church where she sings and touches lots of lives through her prayers and singing that heal many. Some of the church pastors become jealous of her and plot against her which leads to her excommunication from the church. Now that even church has failed her, she resorts to marriage; thinking she will find solace but her husband after losing his job, torments and beats her for reasons uncalled for. He finally dies and she is blamed for his death and consequently she is excommunicated from the village again. Meanwhile she heals the son of one of the churchmen who plotted against her. The man in return decides to confess and the main pastor hearing this goes in search for her to apologise. She is found at the verge of committing suicide but is saved and taken to live with the pastor. Here, life is not still a bed of roses as she suffers torment, persecution and humiliation from the pastor's wife and daughter. In such moments she sings because that is the only thing that gives her solace. After a series of torments, the pastor's daughter realizes her mistake and apologises to Blessing. Blessing continues to have terrible nightmares of her aunt pursuing her with a cutlass and behold her uncle goes to the village only to discover that the aunt is behind Blessing's misfortunes and the death of her parents. The aunt stabs the uncle and herself to death and the movie finally ends with the marriage of Blessing and Amos.

\subsection{Representation of Music as Therapy at Home}

The directors of the two movies have aptly portrayed music as therapeutic especially for children since it provides them with mental and physical relief. No matter how much medicine is given to them, sometimes it is still not enough. Through listening and playing music as well as song 
writing and singing, pain among patients reduces resulting in physiological changes including improved respiration, lower blood pressure, improved cardiac output, reduced heart rate and relaxed muscle tension. According to psychology today, all forms of music may have therapeutic effects although music from one's culture may be most effective. This is evident from the movies under study. In A Cry for Help, Blessing through her singing heals a lot of people. The pastor even attests to this when he tells her, 'You have healed and touched so many people's lives through prayers and singing'. The images below show Blessing in the house, hospital and in church after she sings and heals some children.

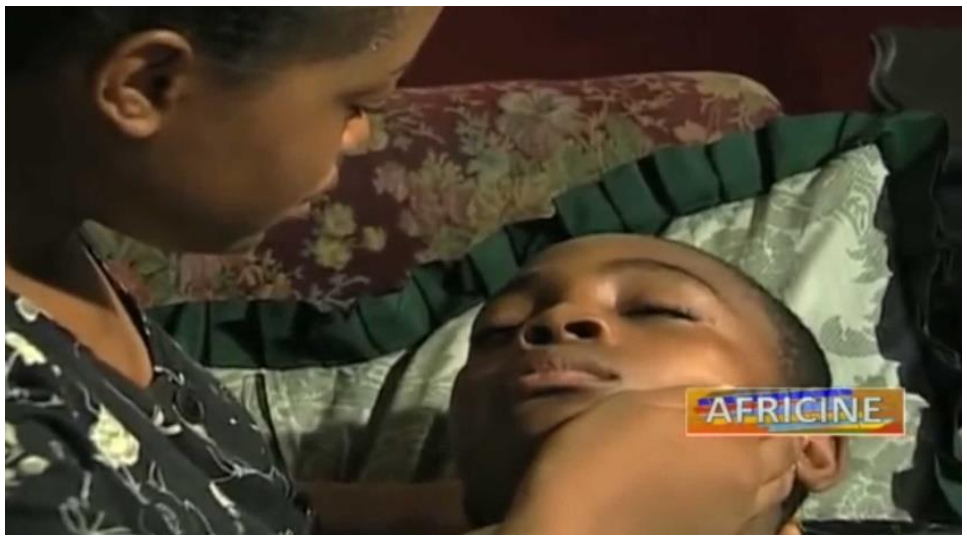

\section{Healing At Home Through Singing A Cry for Help Part One; 20:44 sec.}

This picture shows that music really heals where other forms of medication have failed. This is Blessing at home with Junior; her madam's son after the movie has played for 20:44 seconds. Her madam cautions her to take care of her son who is seemingly ill while she rushes out to probably buy some medicine. Immediately she leaves, Junior starts coughing and is at the verge of dying when Blessing not knowing what to do lays her hand on him and starts singing this song '......he holds the key to your life (2x) when sickness and trouble seem to take your soul away, he holds the key to your life...' As she sings, Junior wakes up instantly. This is indicative of the healing power of music and this suits the theme of the film. The close-up shot shows that the little boy is in dire need of healing and Blessing's singing is timely enough.

\subsection{Healing Power of Music at the Hospital}

In the hospital in part two of the movie 1:33:22 of A Cry For Help, Blessing lays her hand on the little boy who has been on coma for days, and starts singing '... he holds the key to your life (2x) when sickness and trouble seem to take your soul away, he holds the key to your life...' As she sings this boy gradually wakes up. The mother of the boy and the nurses are flabbergasted as they have given him tablets and injections to no avail. In fact they had done all within their medical power to save the little boy and finally abandoned him with the mother. Yet, just a song 
is enough to heal this boy as seen in the picture below. The long shot exposes us to the surprise on the faces of those at the hospital ward at the coming to life of this little boy.

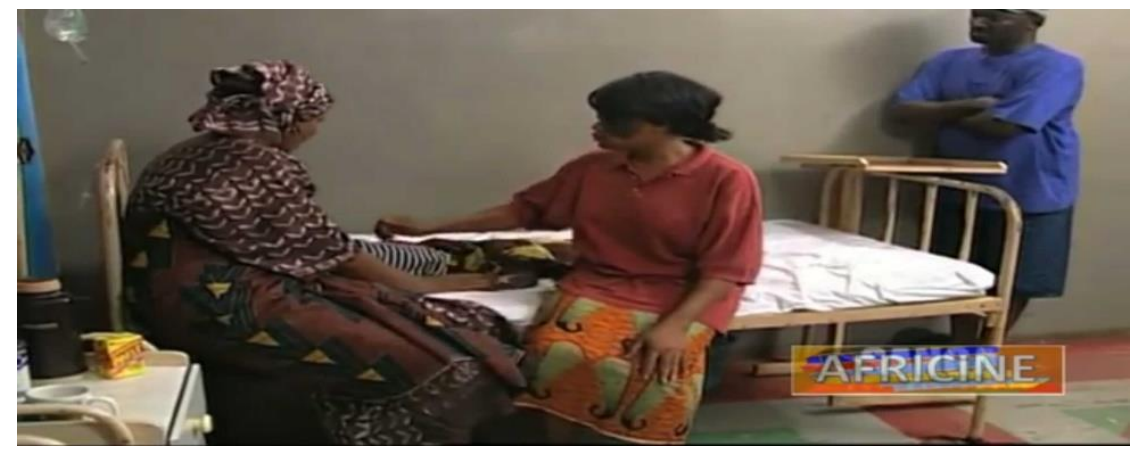

Healing at the Hospital, A Cry for Help Part Two; 1:33:22sec.

\subsection{Healing at Church Using Music}

This lady's son falls terribly sick and from her conversation with her friend, we can tell that she has moved from hospital to hospital with the son to no avail. This time around she rushes with the child to church while Blessing is in church singing as she enters unnoticed with her breathless child. While singing continues, the little boy is awoken miraculously to the amazement of everyone after the movie has played for 1:57:26. Equally, in church, people sing to feel better and forget their problems since music has a soothing effect

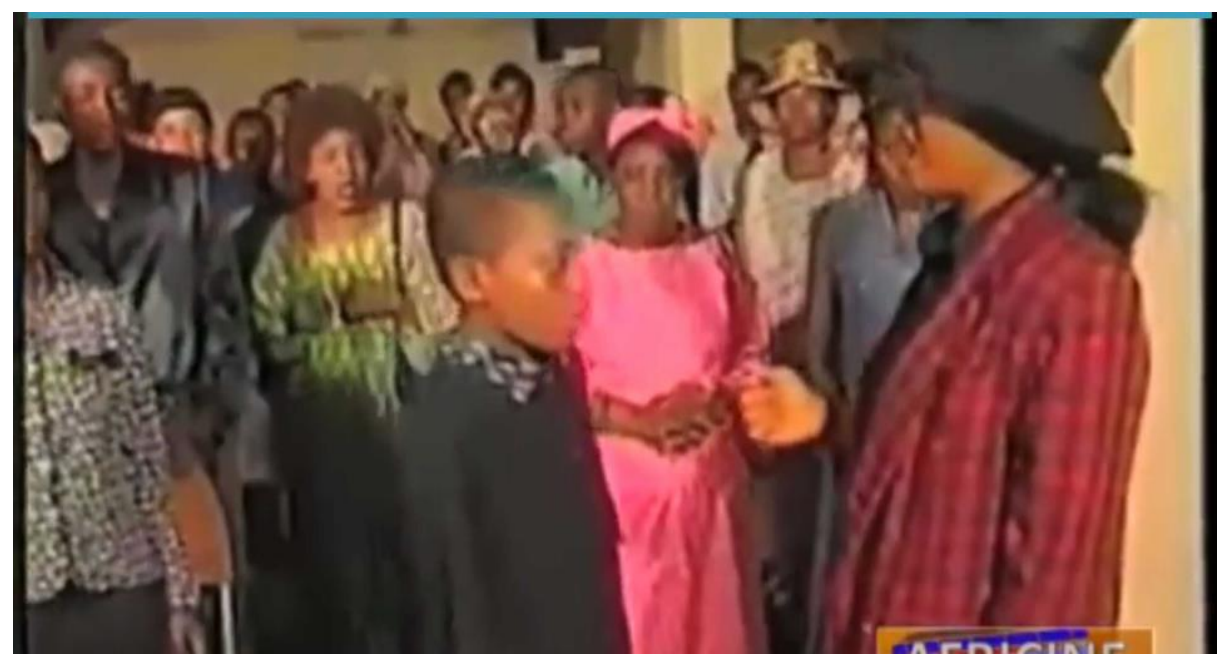

Healing of Little Boy in Church Through Singing in A Cry for Help, Part One; 1:57:26sec 4.5. Power of music to reduce stress 
Another therapeutic effect of music exemplified in the movies is in its power to reduce stress. Stress is an illness that affects the body in several ways. Some common effects of stress on the body is that it causes headache, muscle tension, fatigue, sleep problems as well as chest pain. These often make a person depressed and angry. One of the best remedies for stress is music since it helps to fight stress and depression. Normally a person becomes stressed up when the serotonin levels are low and since music boosts the secretion of serotonin which lowers stress hormone levels, this helps to overcome stress and anxiety. Thus many people are often advised to pick up a musical instrument or sing the songs they like as it helps cope with stress. No wonder Joe in Passion of the Soul plays his guitar after Najah's father refuses him from marrying her. He's in a bad mood after he becomes nostalgic about his past love experiences with Najah. He has only his guitar to console and help him forget those hurtful past experiences as portrayed by the image below in part one of Passion of the Soul 57:36. This action of his further emphasizes the theme of love in the movie. The straight-on angle from which the camera is tilted reveals Joe's facial mood which shows that he's at sixes and sevens.

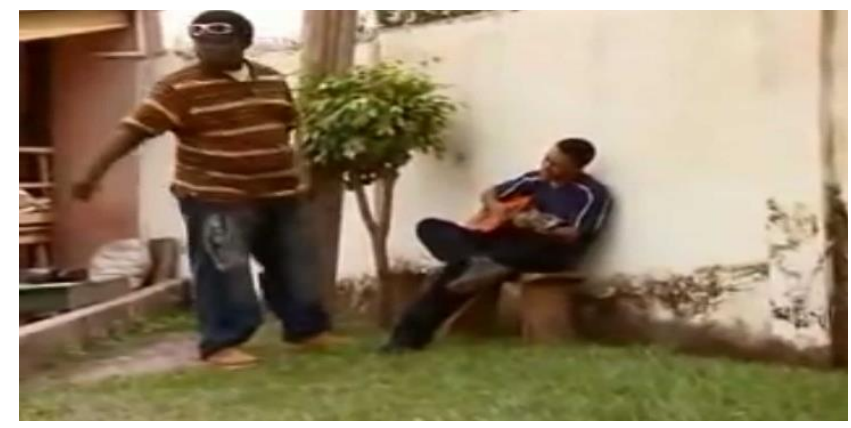

\section{Joe playing his guitar in part one of Passion of the Soul 57:36}

Also, in Passion of the Soul, the movie begins with Blessing completely stressed up. She is lamenting on her parent's grave while crying and singing in the dialect '...ebobasikiri mesiwa $2 \mathrm{x}$ ebobasiki ebobasiki2x ...' Singing gives her the strength she needs to push forward as an orphan. The cross here is a symbol of death and just by seeing it gives Blessing the zeal to die and meet her parents. This makes her sad always. She cannot help but sing to get herself off such feelings. The fact that the story is told from the first person's point of view makes the audience to empathize better with Blessing. 


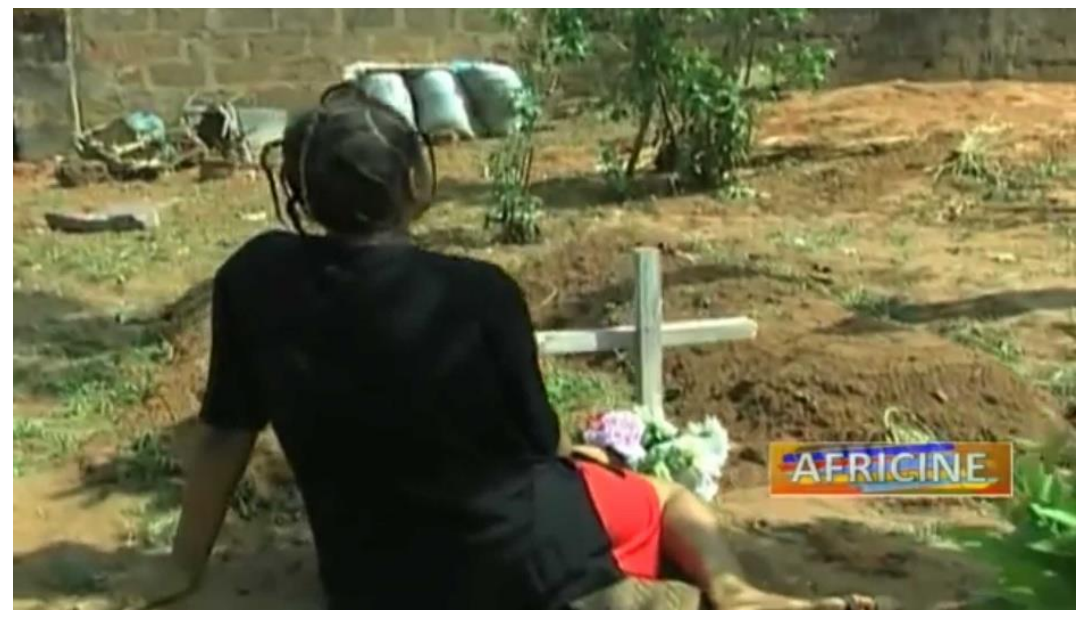

\section{Blessing Singing On Parent's Grave As Part One of Passion of the Soul begins}

In the same light, Blessing sings the same song

“...ebobasikiri mesiwa $2 \mathrm{x}$

ebobasiki ebobasiki 2 x ...'

When her madam scolds and beats her for not doing laundry on time as shown in this conversation:

Madam: what are you still waiting for?

Blessing: I'm eating my food

Madam: (beats her mercilessly and throws the food on her face saying) What are you eating when you have done nothing? You have fetched water all day? Idiot! Nonsense!

Blessing becomes devastated and can only sing at this point as she looks up to heaven while singing. Music is the only thing that keeps her at peace after all the trauma. It equally gives her the strength needed for her to work as seen in the photo below. The close-up shot is telling of her devastated state and reveals the internal conflict Blessing has been battling with for a long time. 


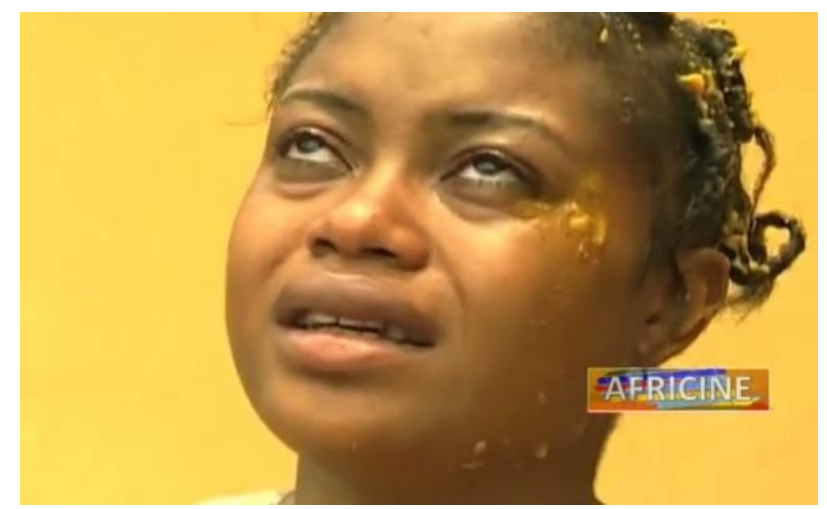

Blessing Looks up To Heaven While Singing; A Cry for Help Part one, 15:11sec

Moreover, after the movie has played for 28:05, Blessing recalls her sorrowful moments ranging from maltreatment from her madam to the death of her parents, she feels depressed and starts singing '...my God I cannot make it again, my heart is failing me, all my hope is gone, nobody cares, I will take it over with the Lord, I know, yes I know He will listen...' From this we can really tell that she is disillusioned and traumatised and music serves as her only therapy. It becomes her pain and cure as she cries at the same time while singing as seen in this photo. The lyrics of the song tell us that it has a religious undertone and Christians believe that in moody moments, God becomes their strength and refuge as he is the only one who can carry their burdens. The choice of Blessing's song who is equally a staunch Christian highlights this belief. The lighting effect of the dark night is revealing of Blessing's agony and melancholy and even her sitting posture, with hands supported on the jaw while tears of sorrow are dripping from her eyes down her cheeks only go a long way to heighten her depression.

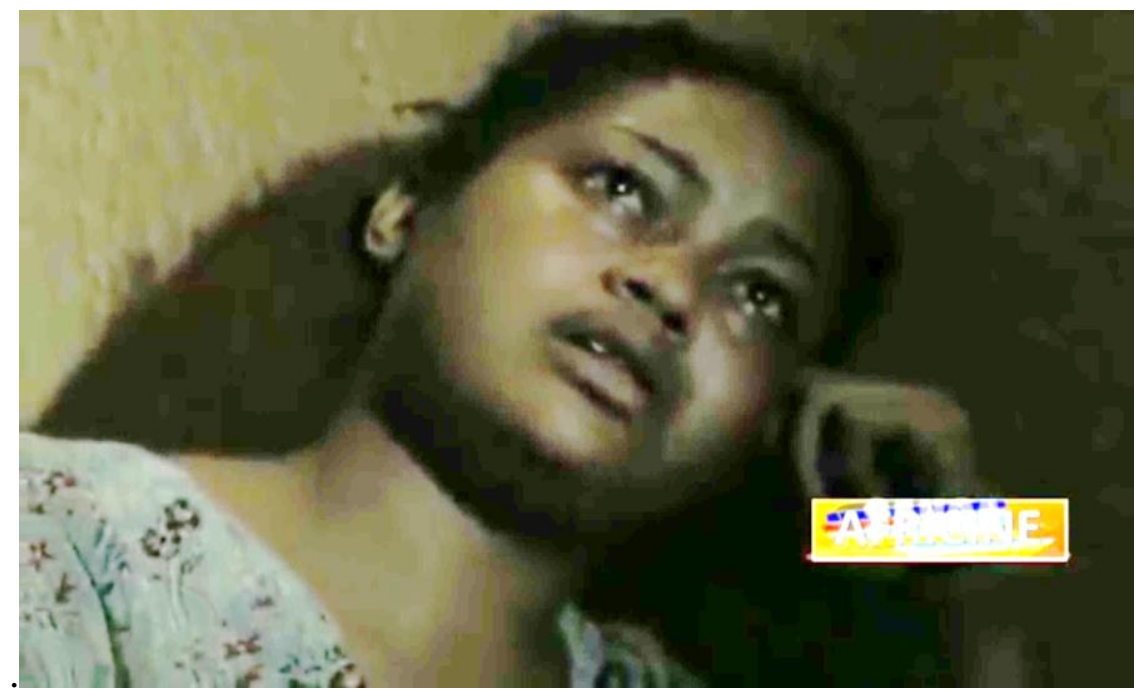

Blessing Sings to Reduce Stress in A Cry For Help Part One: 28:05 


\subsection{Power of Music to Improve Mood}

In addition, music helps to improve one's mood and increases self-esteem as portrayed by the directors in the two movies. It can motivate and boost self-confidence. Remember that stress affects mood in that it makes one sad, angry, restless and anxious. Music is often linked to moods and certain songs can make individuals feel a variety of emotions from happy, calm, energetic or relaxed. For instance, when the movie Passion of the Soul begins, a maid is singing '...oh Najah you are so beautiful2x oh Najah you are so pretty oh Najah you are an angel, oh Najah, Najah Sarbah ...' to Najah who is completely in tears. This is because she is about to marry a man she does not love; a decision made by her own father, an archaic African culture where parents still believe they can choose spouses for their children. The song in a way helps build her morale and motivates her to stop crying thereby improving her mood to face her marriage. The long-shot reveals the maid singing and another wiping the tears of sorrow from Najah's face on her own wedding day. As a romantic genre, this keeps the audience at a suspense as to what will happen next, will she turndown the marriage and marry the love of her life or finally please her father and live in sorrow while hoping that love grows?

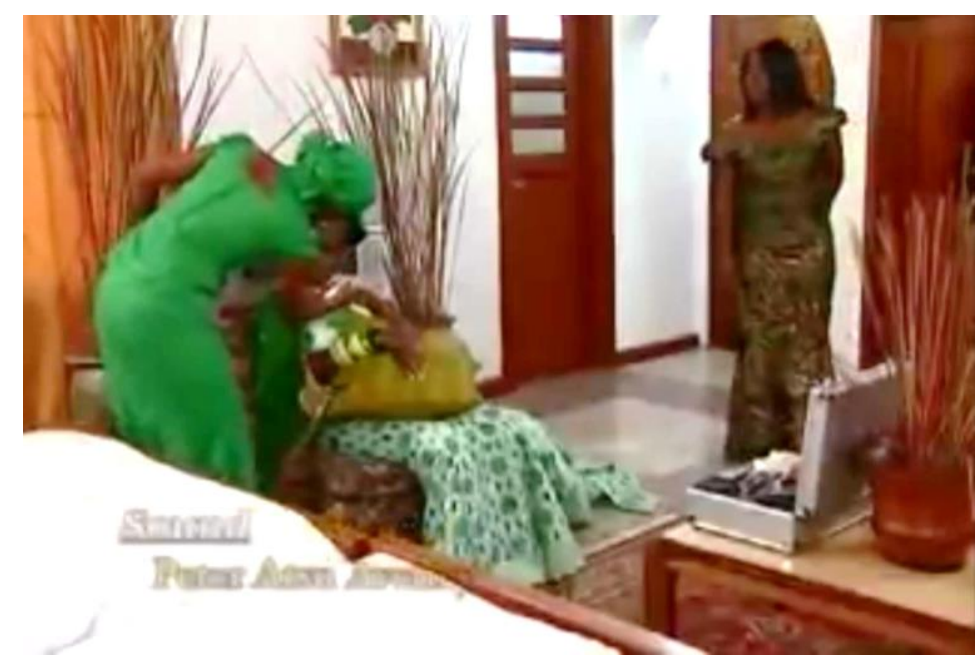

\section{Maid singing to Najah as Passion of the Soul commences}

In her moody moments in A Cry for Help, Blessing engages herself in singing. The songs she sings enhances the atmosphere of the movie and suits the theme of the movie. For instance, she sings when accused of killing her husband and is consequently locked in the same room with the corpse where she spends the night 1:39:50 in part two. The dark room and dark clothes she's wearing and the state of being locked up in a room with a corpse reveals Blessing trauma and sorrow. 
Still in Part 2, 1:52:36, Blessing is seen singing on her way to commit suicide after her excommunication from the village for the death of her husband. She is in black clothes which are a symbol of death and the solemnity of the forest where she walks plus the background sound all indicate that the end is near for Blessing. After her excommunication from the village, Blessing no longer has reasons to live and while thinking of the next move, we see her singing because she is actually in pain and moody. Since music is believed to make people die peacefully, this makes the audience sympathise with Blessing on her way to Calvary though she braves it with singing.

In addition, the pastor's daughter accuses Blessing of insulting her, she receives snake beating from the pastor's wife and daughter and becomes very moody. As such she starts singing and crying in her room 2:44:36 as she can no longer put up with the external conflict she has been enduring. Her sitting posture at the edge of the bed with head resting against the wall makes us feel her devastation more.

Finally, after viewing the movie for 2:46:44, Blessing is seen parking her stuff to leave the pastor's house while crying and singing. She has just been accused of theft by Cynthia; pastor's daughter. She is again beaten pitilessly by Cynthia and her mother for stealing Cynthia's money and things. This time pepper is rubbed into her eyes whereas she is innocent. Blessing finds herself in an imbroglio and in a bit to improve her mood even when everything seems to be working against her, music becomes the only therapy during such moments. The pictures below clearly portray Blessing during those precarious moments.

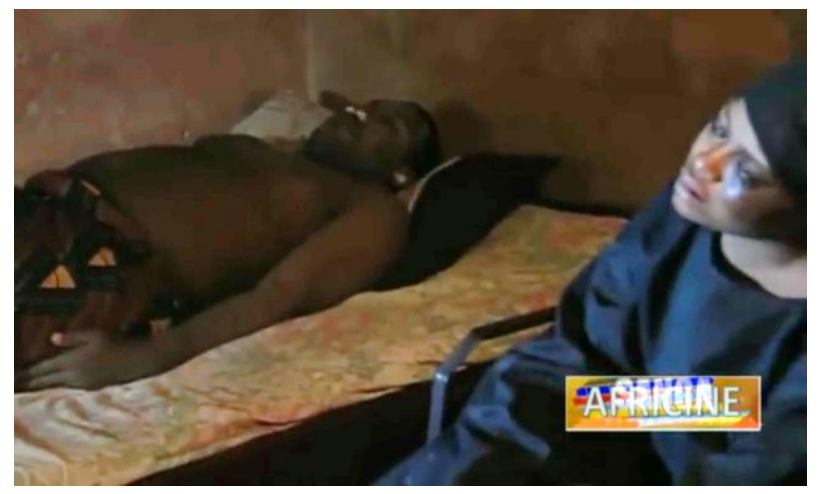

Blessing With Dead Husband. A Cry For Help Part Two; 1:39:50 


\section{International Journal of Arts and Humanities}

ISSN: 2581-3102

Volume: 04, Issue: 02 "February 2020"

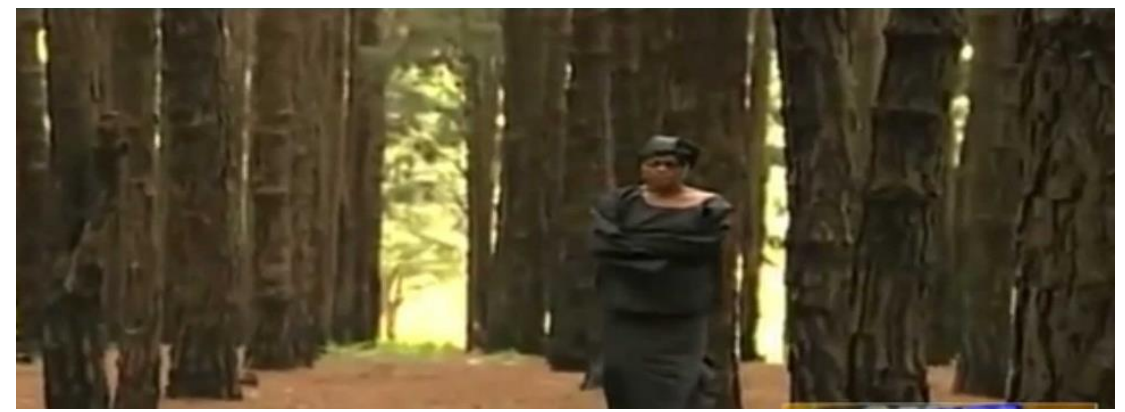

\section{Blessing Singing about to Commit Suicide A Cry for Help part 2; 1:52:36}

\section{CONCLUSION}

Music and its aesthetics cannot be over emphasized. It had existed in the past and still dwells in the present even in movies. Hardly can one find any culture without music. Have you ever thought of how life would be without music? Well, we did in this research and found that the world would be a quiet place. So far our analysis has shown music as something extraordinary; it is what makes humans human. Music is in a number of ways the fabric to our lives and the definition of society as everyone enjoys music. Through its relaxing and soothing effect, it can make our bad days better.

Music is a universal language that has the ability to evoke deep feelings at the core of shared human experiences. At the individual level, it can induce multiple responses; physiological, mood, emotional, and behavioral. The power of music to act therapeutically has long been recognized as seen in the movies. The increased availability of music seems to be encouraging people to use music to manipulate their own moods, reduce stress, alleviate boredom while doing tedious work and create environment appropriate for particular kinds of social occasion. In short, music is being used by individuals to enhance the quality of their lives.

In this study, after watching the two movies, we examined its therapeutic representation. Both movies showcased music as healing and beneficial to our health. In A Cry for Help, there are several instances where Blessing uses music to heal children in a lifeless state as well as to heal herself of stress just like in Passion of the Soul where music seems to be Joe's only therapy in his stressful moments. The directors equally indicated music as something that can be used to improve people's mood as it is what keeps Blessing going in several scenes of A Cry for Help and Najah in Passion of the Soul.

\section{REFERENCES}

Aigen K.(1991). The Voice Of The Forest: A Conception Of Music For Music Therapy. Journal of Music Therapy Vol.10, No.1,77-98 
International Journal of Arts and Humanities

ISSN: 2581-3102

Volume: 04, Issue: 02 "February 2020"

Charles O.A(2010). Some Reflections on the Future of Music Therapy in Nigeria. Journal of Language, Technology and Entrepreneurship in Africa vol.2.No.1.2010

Dawn Kent (2006). The Effect of Music on the Human Body and Mind. Unpublished master's thesis, Liberty University Spring.

Gallant, W.\& Holosko,M.(1997). The Use of Music in Counseling Addictive Clients. Journal of Alcohol and Drug Education,42,42-52.

Hendricks, C.B, Robbinson, B., Bradley, L. J, Davis, K (1999). Using Music Techniques to Treat Adolescent Depression. Journal of Humanistic Counseling, Education \& Development,38,39-46.

Trehan, S. (2004). Music to My Ears. Journal of Palliative Medicine,7,868-869 